\title{
NANOFLUID PROPERTIES FOR FORCED CONVECTION HEAT TRANSFER: AN OVERVIEW
}

\author{
W.H.Azmi ${ }^{1}$, K.V. Sharma ${ }^{2}$, Rizalman Mamat $^{1}$ and Shahrani Anuar ${ }^{1}$ \\ ${ }^{1}$ Faculty of Mechanical Engineering, \\ Universiti Malaysia Pahang, 26600 Pekan, Pahang, Malaysia \\ Email:wanazmi2010@gmail.com \\ ${ }^{2}$ Department of Mechanical Engineering, \\ JNTUH College of Engineering, Manthani, 505212, Andhra Pradesh, India
}

\begin{abstract}
Nanofluids offer a significant advantage over conventional heat transfer fluids and consequently, they have attracted much attention in recent years. The engineered suspension of nano-sized particles in a base liquid alters the properties of these nanofluids. Many researchers have measured and modeled the thermal conductivity and viscosity of nanofluids. The estimation of forced convective heat transfer coefficients is done through experiments with either metal or nonmetal solid particles dispersed in water. Regression equations are developed for the determination of the thermal conductivity and viscosity of nanofluids. The parameters influencing the decrease in convection heat transfer, observed by certain investigators, is explained.
\end{abstract}

Keywords: Forced convection; heat transfer enhancement; nanofluid; thermal conductivity; viscosity.

\section{INTRODUCTION}

Fluids containing small quantities of particles with magnitudes lower than $100 \mathrm{~nm}$ dispersed in a continuous medium, such as water, ethylene glycol, and engine oil, are termed 'nanofluids'. Rao, Sharma, Chary, Bakar, Rahman, Kadirgama and Noor (2011) and Sundar and Sharma (2011a) have studied the forced convection heat transfer using nanofluids for different applications. The thermo-physical properties of nanofluids are higher than those of the base liquids. Eastman, Choi, Li, Thompson and Lee (1997), Lee, Choi, Li and Eastman (1999), and Wang, Xu and Choi (1999) all observed higher values of nanofluid thermal conductivity compared with the base liquid. The properties of aluminum oxide and copper oxide nanofluids based on water and ethylene glycol have been investigated widely because of their potential as heat transfer fluids in automotive and electronic cooling applications (Maïga, Nguyen, Galanis, Roy, Maré \& Coqueux, 2006; Wen \& Ding, 2004; Vijaya Lakshmi, Subrahmanyam, Dharma Rao, \& Sharma, 2012). The classical analysis of Maxwell (1904) for two-phase solid-liquid mixtures is the basis for the determination of the effective thermal conductivity of nanofluids. The model's predictions are satisfactorily for spherical-shaped particles at low-volume concentrations at ambient temperatures. The thermal conductivity of micron-sized solid suspensions is estimated using the Maxwell (1904) model. However, the model fails to predict the thermal conductivity of nanofluids. 


\section{Thermal Conductivity: Theoretical Models}

The model of Hamilton and Crosser (1962) is used widely for comparison of experimental data obtained by different investigators. The model is effective so long as the thermal conductivity of the particles is 100 times greater than the conductivity of the continuous phase. The influence of particle size and temperature is not considered in the model. The thermal conductivity predicted by the model is lower compared with experimental values. Yu and Choi (2003) modified Maxwell's model to predict the effective thermal conductivity of nanofluids. They assumed that the base fluid molecules close to the surface of the nanoparticles build a solid-like layered structure that has higher thermal conductivity than that of the base fluid. They combined the thermal conductivities of the solid particles and the nano-layer to arrive at an equivalent thermal conductivity of the nanofluid. Koo and Kleinstreuer (2005) proposed a model to determine the effective thermal conductivity of a nanofluid as the sum of Maxwell's model and a term related to Brownian motion. This takes into account the effect of particle size, volume concentration, temperature, and properties of base fluid, as well as the nanoparticles subjected to Brownian motion. The combined Maxwell-Garnett conduction and convection, caused by the Brownian motion of the suspended particles, is the basis for thermal conductivity enhancement, according to Prasher, Bhattacharya, and Phelan (2006). According to Jang and Choi (2007), there are four modes that contribute to the energy transfer responsible for the enhancement of the thermal conductivity of nanofluids. The first mode is collision between the base fluid molecules; the second is thermal diffusion in nanoparticles; the third is collision of nanoparticles with each other due to Brownian motion; and the fourth is collision between base fluid molecules and nanoparticles by thermally induced fluctuations. Vajjha and Das (2009) measured the thermal conductivities of $\mathrm{Al}_{2} \mathrm{O}_{3}$, copper oxide, and zinc oxide nanofluids with nanoparticles dispersed in ethylene glycol (EG) and water in the ratio of 60:40 by mass. They conducted experiments in the temperature range of 298 to $363 \mathrm{~K}$ up to $10 \%$ volume concentration and developed a correlation for the estimation of nanofluid thermal conductivity similar to that of Koo and Kleinstreuer (2005). It can be observed that different models have been developed to determine the thermal conductivity of nanofluids with the consideration of Brownian motion or with the concept of an interface between the particle and the liquid. Certain models include a parameter such as the mean free path of water, which is used in the process of obtaining dimensionless terms. Thus, theoretical determination of nanofluid thermal conductivity is semi empirical and material dependent.

\section{Thermal Conductivity: Experimental Observation}

It can be observed that the theoretical models developed used certain empiricism in their equations. Hence, the determination of thermal conductivity based on experimentation has continued since the work of Lee et al. (1999), using the concept of heat conduction under steady or transient methods. The experiments by Pak and Cho (1998) may be considered as pioneering work in estimating the properties of $\mathrm{Al}_{2} \mathrm{O}_{3}$ nanofluid for the determination of heat transfer coefficients in the turbulent range. Lee et al. (1999) conducted experiments for the determination of thermal conductivity in water and EG using $\mathrm{Al}_{2} \mathrm{O}_{3}$ and $\mathrm{CuO}$ nanoparticles of 38 and $24 \mathrm{~nm}$, respectively. The experimental data with $\mathrm{Al}_{2} \mathrm{O}_{3}$ /water and $\mathrm{Al}_{2} \mathrm{O}_{3} / \mathrm{EG}$ are in reasonable agreement, whereas those from $\mathrm{CuO}$ /water and $\mathrm{CuO} / \mathrm{EG}$ nanofluids showed higher values when compared with the 
Hamilton-Crosser model. They reasoned that they obtained lower values of thermal conductivity with $\mathrm{Al}_{2} \mathrm{O}_{3}$ /water due to the larger particle size of $38 \mathrm{~nm}$ that they used, when compared with the values of Masuda, Ebata, Teramae, and Hishinuma (1993) who used 13-nm-sized particles. However, the deviation of the experimental values of $\mathrm{CuO}$ nanofluids with Hamilton and Crosser could not be explained. Das, Putra, Thiesen, and Roetzel (2003) observed the thermal conductivity of $\mathrm{CuO} /$ water nanofluid to rise from $2 \%$ to $10.8 \%$ at $1 \%$ and from $9.4 \%$ to $24.3 \%$ at $4.0 \%$ volume concentration when measured at temperatures between 21 and $55{ }^{\circ} \mathrm{C}$. They reasoned that the Hamilton-Crosser equation could not predict the temperature dependence of the nanofluid. Consequently, values evaluated with the equation are lower than those obtained from experiment are. Chon, Kihm, Lee \& Choi (2005) proposed a semi empirical correlation for the determination of the thermal conductivity of an $\mathrm{Al}_{2} \mathrm{O}_{3}$ nanofluid considering Brownian motion. Mintsa, Roy, Nguyen, and Doucet (2009) conducted experiments to determine the thermal conductivity of aluminium oxide and copper oxide nanofluids in the temperature range of $20-50{ }^{\circ} \mathrm{C}$ and up to $18 \%$ volume concentration. All these experiments have predicted increasing values of thermal conductivity with concentration and temperature, and the values varied depending on the material. No significant variation in thermal conductivity can be observed between aluminum and copper oxide nanofluids. The thermal conductivity decreased with an increase in particle size at different volume concentrations. The investigators did not consider the influence of particle size in the development of their regression equations.

\section{Viscosity of Nanofluids: Theoretical Models}

The viscosity of nanofluids has been investigated less than the thermal conductivity. Studies on the rheological properties of liquid suspensions commenced with Einstein's classical analysis. The Einstein equation can predict the effective viscosity of liquids in the low-volume fraction having spherical suspended particles. Brinkman (1952) extended the applicability to $4.0 \%$ particle volume concentration. With increasing particle volume concentration, the neighboring particles affect the nature of flow around a particle. Batchelor (1977) studied the effect of these hydrodynamic interactions or the Brownian motion on the viscosity of suspensions and developed a relationship that is valid for particle volume concentrations up to $10 \%$.

\section{Viscosity of Nanofluids: Experimental Observation}

The viscosity of nanofluids has been determined experimentally by many researchers. Pak and Cho (1998) observed Newtonian behavior with $\mathrm{Al}_{2} \mathrm{O}_{3}$ and $\mathrm{TiO}_{2}$ nanofluids at particle volume concentrations of less than $3 \%$ and $10 \%$ and for average diameters of 13 and $27 \mathrm{~nm}$, respectively. They observed that the viscosity decreased with temperature, although the viscosity of the nanofluid is much higher than that of the base fluid. Batchelor's model failed to predict the viscosity of the nanofluids, although the volume fraction of the particles is within the range of applicability. Nguyen, Desgranges, Roy, Galanis, Maré, Boucher, and Angue Mintsa (2007) conducted experiments under ambient conditions, using different concentrations and particle sizes, to determine the viscosity of $\mathrm{Al}_{2} \mathrm{O}_{3}$ and $\mathrm{CuO}$ nanofluids in water. Experiments revealed that the viscosity of $\mathrm{Al}_{2} \mathrm{O}_{3}$ with particle sizes of 36 and $47 \mathrm{~nm}$ and that of $\mathrm{CuO}$ with particle sizes of $29 \mathrm{~nm}$ predicted similar values for volume concentrations of less than $4 \%$. Hence, the viscosity is independent of the properties of the material. Das et al. (2003) developed a 
regression equation for the viscosity ratio as a function of concentration and particle diameter. Lee, Hwang, Jang, Lee, Kim, Choi, and Choi (2008) conducted experiments with an $\mathrm{Al}_{2} \mathrm{O}_{3}$ nanofluid in the volume concentration of less than $0.3 \%$ with $30-\mathrm{nm}$ sized particles in the temperature range of 21 to $39^{\circ} \mathrm{C}$. The values of viscosity determined were always higher than those of the base liquid. The nanofluid viscosity increases with volume concentration and decreases with temperature. The influence of material on viscosity is insignificant for volume concentrations of nanofluid up to $4.0 \%$. The relative increase in viscosity can offset the advantage of enhanced thermal conductivity. Hence, the viscosity to thermal conductivity enhancement ratio can be an influential parameter on heat transfer enhancement.

\section{PROPERTIES EVALUATION}

\section{Regression Model of Thermal Conductivity}

The thermal conductivity data of metal and metal oxide nanofluids available in the literature are used in the development of regression equations. Pak and Cho (1998), Williams, Buongiorno, and $\mathrm{Hu}$ (2008), Lee et al. (1999), Murshed, Leong and Yang (2005), Das et al. (2003), Chon and Kihm (2005), Mintsa et al. (2009), Beck, Yuan, Warrier, and Teja (2009), Avsec (2008), Duangthongsuk and Wongwises (2009), Sundar, Naik, Sharma, Singh, and Siva Reddy (2011), and Hong, Kim, and Kim (2007) have all conducted experiments for the determination of thermal conductivity of nanofluids. Thermal conductivity depends primarily on the choice of material, concentration, temperature, and particle size. The influence of material on nanofluid thermal conductivity data is affected through the thermal diffusivity ratio of particles to water $\left(\alpha_{p} / \alpha_{w}\right)$. Experimental values comprising 252 data points are used in the regression analysis to develop a correlation for the determination of thermal conductivity $k_{n f}$, given by:

$$
k_{n f}=k_{w} 0.8938\left(1+\frac{\phi}{100}\right)^{1.37}\left(1+\frac{T_{n f}}{70}\right)^{0.2777}\left(1+\frac{d_{p}}{150}\right)^{-0.0336}\left(\frac{\alpha_{p}}{\alpha_{w}}\right)^{0.01737}
$$

where $\phi$ is the volumetric concentration in $\%, T_{n f}$ is temperature in ${ }^{\circ} \mathrm{C}$, and $d_{p}$ is particle diameter in $\mathrm{nm}$.

The correlation equation is validated with the data shown in the legend of Figure 1 with a maximum deviation of less than $11 \%$ for a few points. The particle sizes and the materials employed by the various investigators in the development of thermal conductivity of Eq. (1) are given in Table 1.

\section{Regression Model of Viscosity}

The experimental viscosity data of Nguyen et al. (2007), Hwang, Jang, and Choi (2009), Wang et al. (1999), Heris, Etemad, and Nasr Esfahany (2006), Nguyen, Desgranges, Galanis, Roy, Maré, Boucher, and Angue Mintsa (2008), Lee et al. (2008), Pak, and Cho (1998), He, Jin, Chen, Ding, Cang, and Lu (2007), Duangthongsuk and Wongwises (2010), and Lee, Park, Kang, Bang, and Kim (2011) for volume concentrations of less than $4 \%$, comprising 233 data points, are subjected to regression, which gives the following correlation: 


$$
\mu_{n f}=\mu_{w}\left(1+\frac{\phi}{100}\right)^{11.3}\left(1+\frac{T_{n f}}{70}\right)^{-0.038}\left(1+\frac{d_{p}}{170}\right)^{-0.061}
$$

Eq. (2) is validated with experimental data, shown as Figure 2, for $C_{1}=1.4$ for $\mathrm{SiC}$ and $C_{1}=1.0$ for metal and metal oxide nanofluids in a water base liquid. The data could be correlated with an average deviation of $3.18 \%$, a standard deviation of $3.8 \%$, and a maximum deviation of $13 \%$. The experimental data of viscosity for different nanofluids and variation of particle diameter are shown in Table 2.

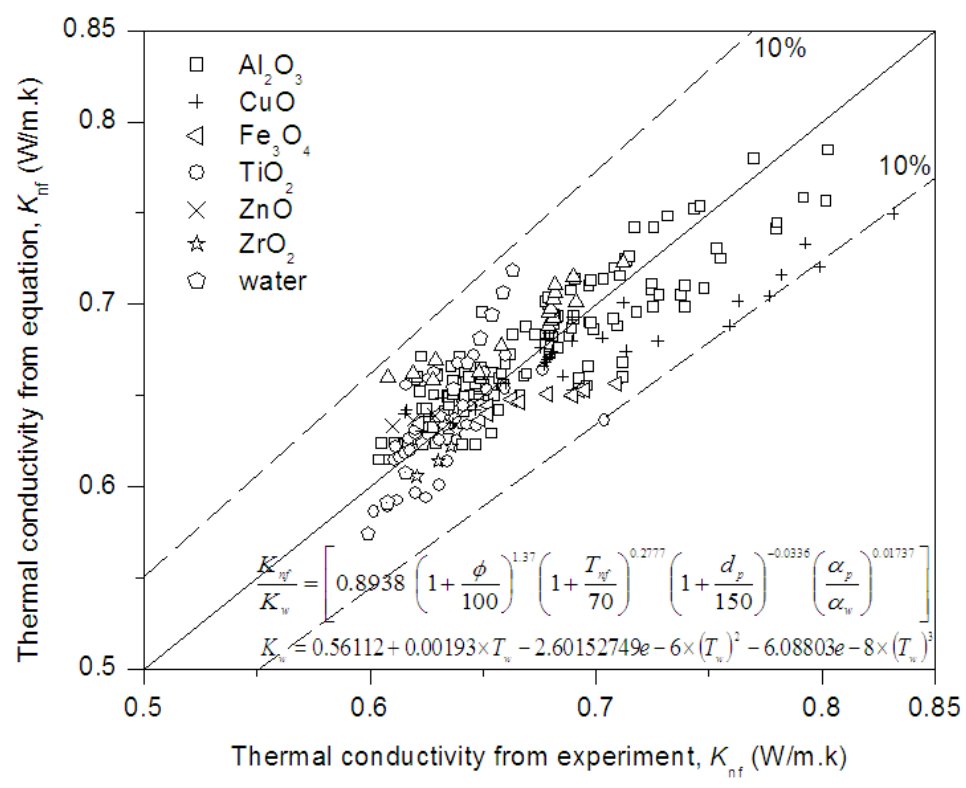

Figure 1. Validation of experimental data with Eq. (1).

Table 1. Experimental data of thermal conductivity from literature.

\begin{tabular}{ccl}
\hline Type of Nanofluid & $\begin{array}{c}\text { Particle Diameter, } \mathrm{d}_{\mathrm{p}} \\
(\mathrm{nm})\end{array}$ & \multicolumn{1}{c}{ Reference } \\
\hline & 38 & Lee et al. (1999) \\
& 38 & Das et al. (2003) \\
& $80 / 150$ & Murshed et al. (2005) \\
& 46 & Williams et al. (2008) \\
& $11 / 47 / 150$ & Chon and Kihm (2005) \\
$\mathrm{Al}_{2} \mathrm{O}_{3}$ & $36 / 47$ & Mintsa et al. (2009) \\
& $8 / 12 / 16 / 46 / 71$ & Beck et al. (2009) \\
& 38.4 & Avsec (2008) \\
& 29 & Das et al. (2003) \\
& 29 & Mintsa et al. (2009) \\
\hline $\mathrm{CuO}$ & 36 & Sundar et al. (2011) \\
\hline $\mathrm{Fe}_{3} \mathrm{O}_{4}$ & 25 & Murshed et al. (2005) \\
& 27 & Pak and Cho (1998) \\
$\mathrm{TiO}_{2}$ & 21 & Duangthongsuk and \\
& $10 / 30 / 60$ & Wongwises (2009) \\
\hline $\mathrm{ZnO}_{\mathrm{ZrO}_{2}}$ & 60 & Hong et al. (2007) \\
\hline & & Williams et al. (2008) \\
\hline
\end{tabular}




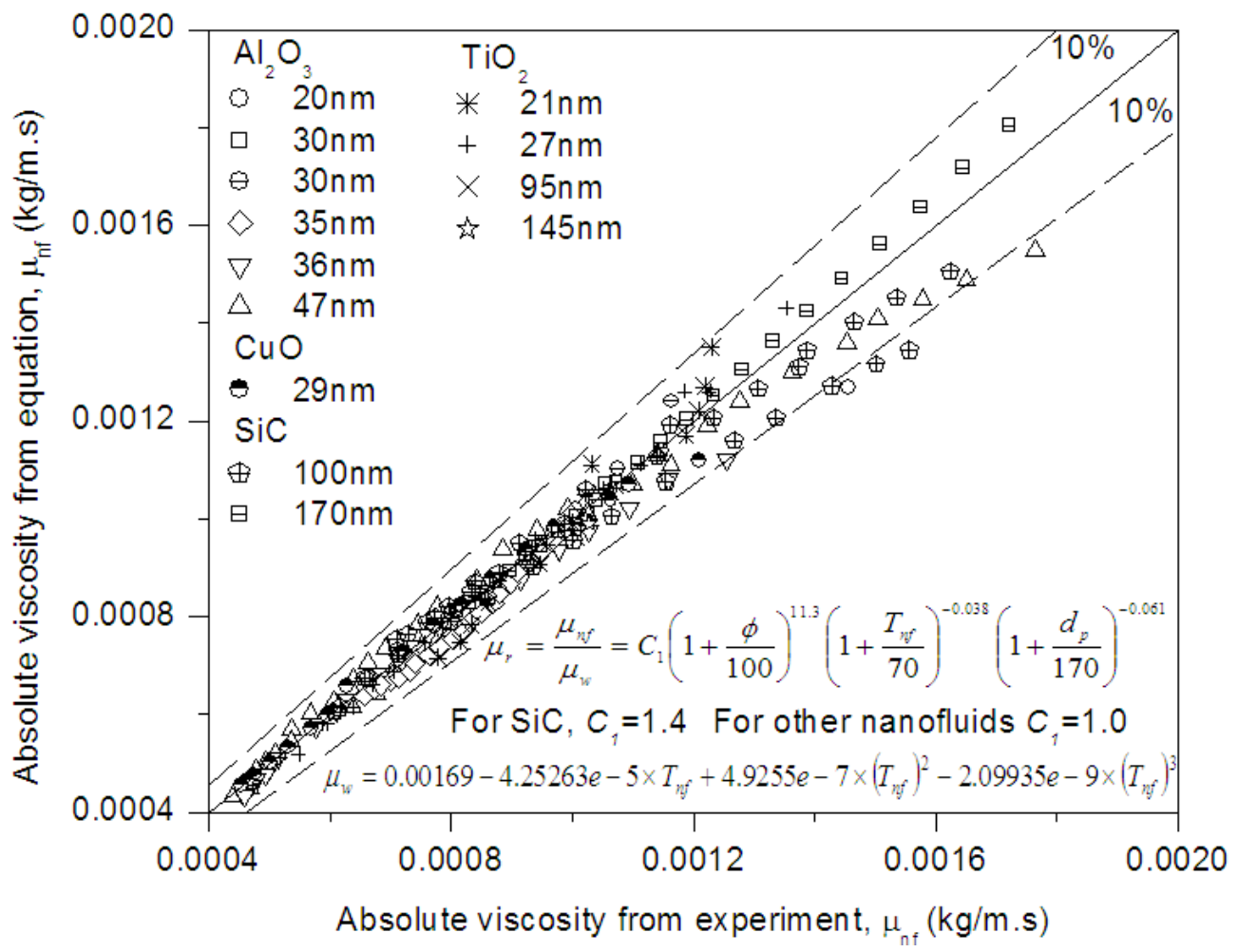

Figure 2. Validation of data with the Eq. (2).

Table 2. Experimental data of viscosity from literature.

\begin{tabular}{ccl}
\hline $\begin{array}{c}\text { Type of } \\
\text { Nanofluid }\end{array}$ & $\begin{array}{c}\text { Particle Diameter, } \\
\mathrm{d}_{\mathrm{p}}(\mathrm{nm})\end{array}$ & \multicolumn{1}{c}{ Reference } \\
\hline & 36 & Nguyen et al. (2007) \\
& 30 & Hwang et al. (2009) \\
& 30 & Wang et al. (1999) \\
$\mathrm{Al}_{2} \mathrm{O}_{3}$ & 20 & Heris et al. (2006) \\
& 47 & Nguyen et al. (2008) \\
& 35 & Lee et al. (2008) \\
\hline $\mathrm{CuO}$ & 29 & Nguyen et al. (2007) \\
\hline $\mathrm{SiC}$ & 170 & Yu et al. (2009) \\
& 100 & Lee et al. (2011) \\
& 27 & Pak and Cho (1998) \\
& 95 & He et al. (2007) \\
$\mathrm{TiO}_{2}$ & 145 & He et al. (2007) \\
& 21 & Duangthongsuk and \\
& & Wongwises (2010) \\
\hline
\end{tabular}

\section{RESULTS AND DISCUSSION}

Nanofluid properties, such as thermal conductivity and viscosity, are essential for the evaluation of heat transfer coefficients under different operating conditions. The opposing nature of the thermal conductivity rise and viscosity decrease with 
temperature, and the dependence of nanofluid thermal conductivity on material properties, alters the range of applicability of nanofluids for heat transfer applications. The estimations of viscosity and thermal conductivity values for metal- and oxide-based nanofluids, for concentrations of less than $4.0 \%$, are evaluated with the regression equations developed. Prasher et al. (2006) developed a condition for heat transfer enhancement based on an order of magnitude analysis. They observed that the ratio of enhancement in nanofluid viscosity to thermal conductivity should be lower than 4.0 in order for the nanofluid to show heat transfer enhancement. However, they did not relate the conditions to temperature and particle size. Pak and Cho (1998) and Duangthongsuk and Wongwises (2010) reported a decrease in heat transfer coefficient with an increase in the concentration of the nanofluid. The regression equations developed for heat transfer could not explain the observations made by these investigators.

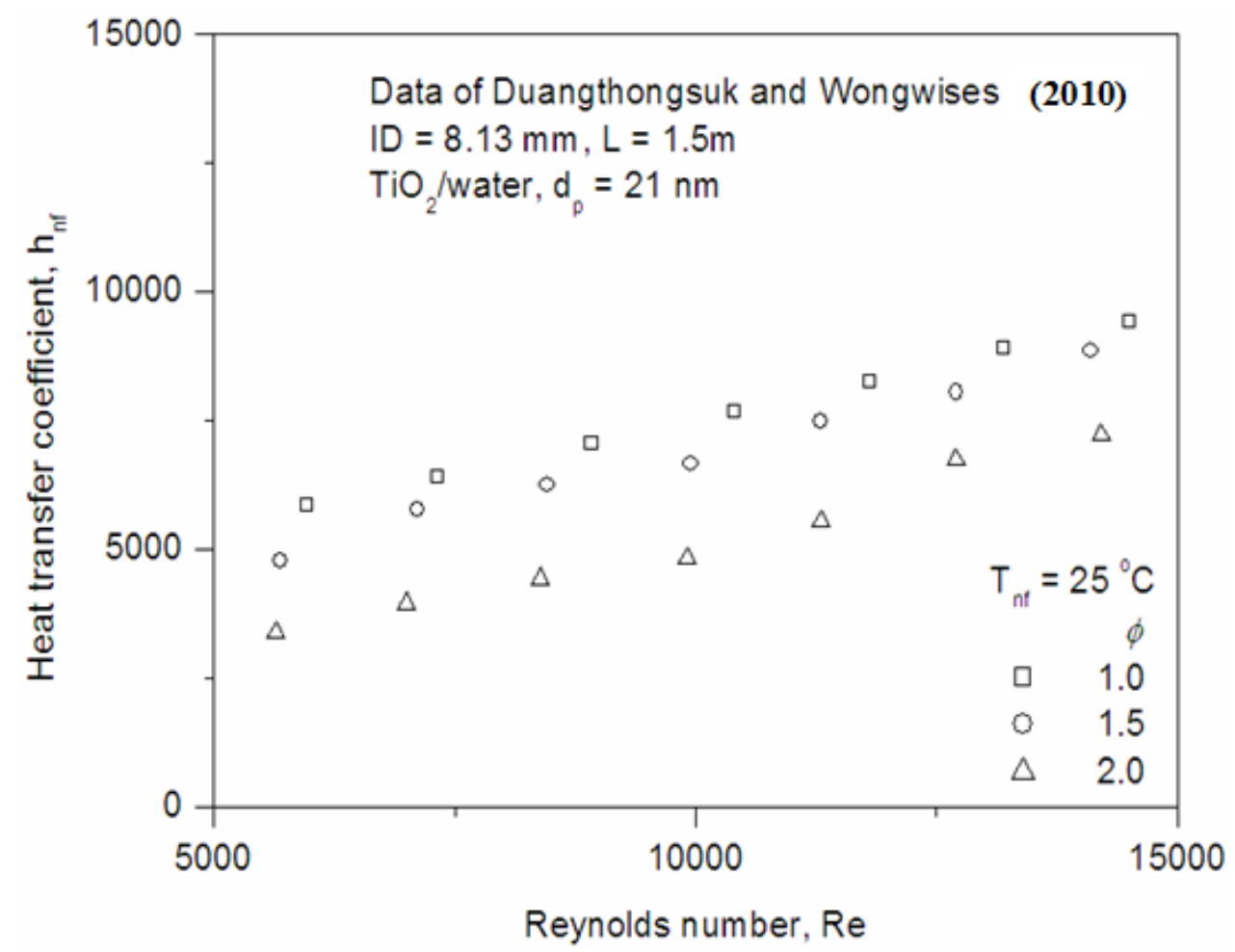

Figure 3. Heat transfer data for $\mathrm{TiO}_{2}$ nanofluids.

The heat transfer data of Duangthongsuk and Wongwises (2010) are shown in Figure 3 for a $\mathrm{TiO}_{2}$ nanofluid undertaken at a temperature of $25{ }^{\circ} \mathrm{C}$. The authors reported a decrease in heat transfer coefficient with increasing concentration. To explain the decrease in heat transfer coefficient, Figure 4 presents the enhancement ratio and nanofluid temperature for 21-nm-sized particles, used by them using Eqs. (1) and (2). According to Prasher et al. (2006), heat transfer enhancements are possible if the viscosity to thermal conductivity enhancement ratio is lower than 4.0, which is shown as the thick horizontal line in Figure 4. As the experiments are undertaken at $25{ }^{\circ} \mathrm{C}$, at all flow rates, the enhancement ratio is less than 4.0 for $1.0 \%$ concentration and greater for $2.0 \%$. The heat transfer coefficient decreased because the enhancement in viscosity is higher than that of thermal conductivity of the nanofluid, when the concentration is increased from $1.0 \%$ to $2.0 \%$, as observed by the investigators. 


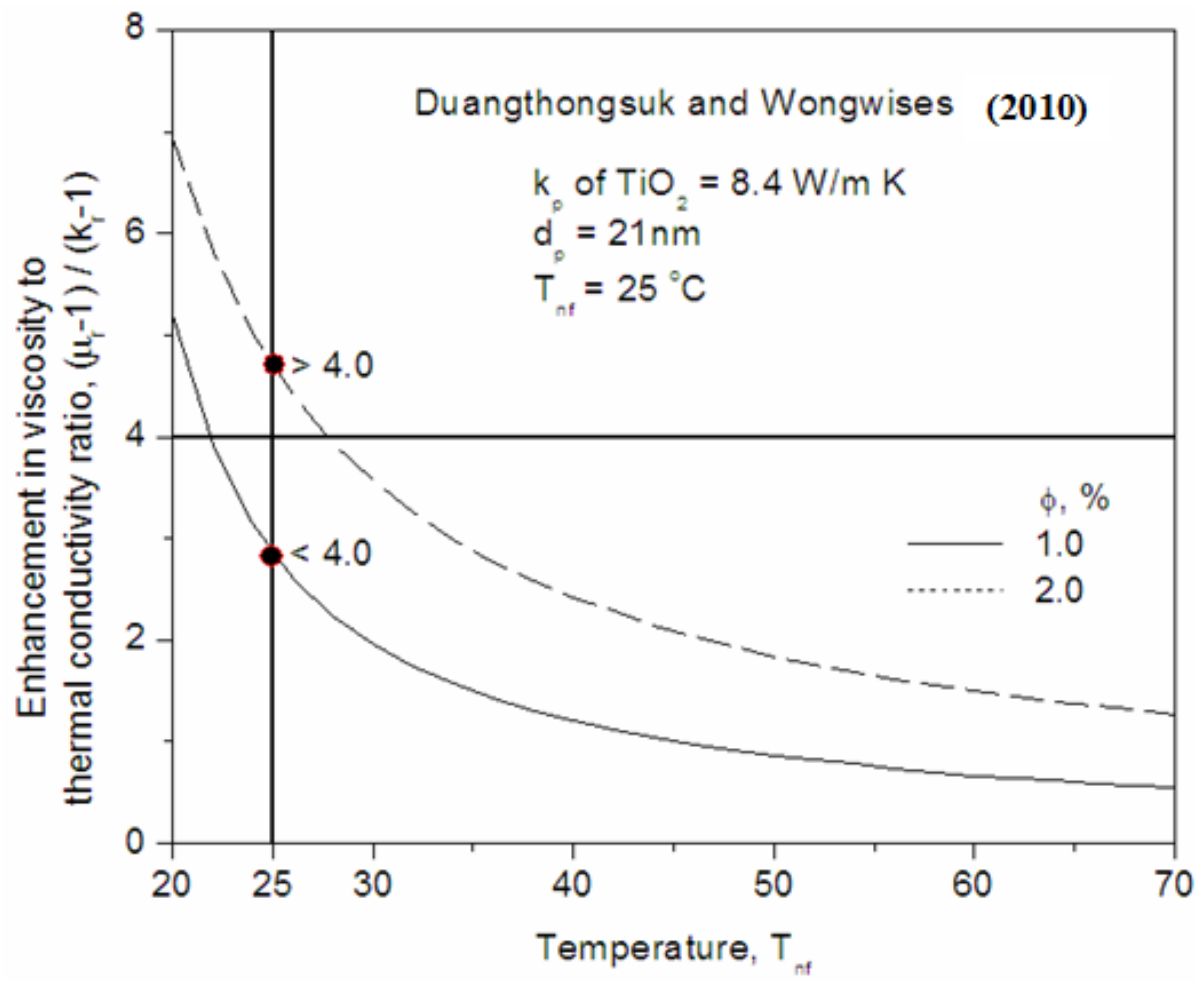

Figure 4. Variation of property enhancement ratio with temperature for $\mathrm{TiO}_{2}$.

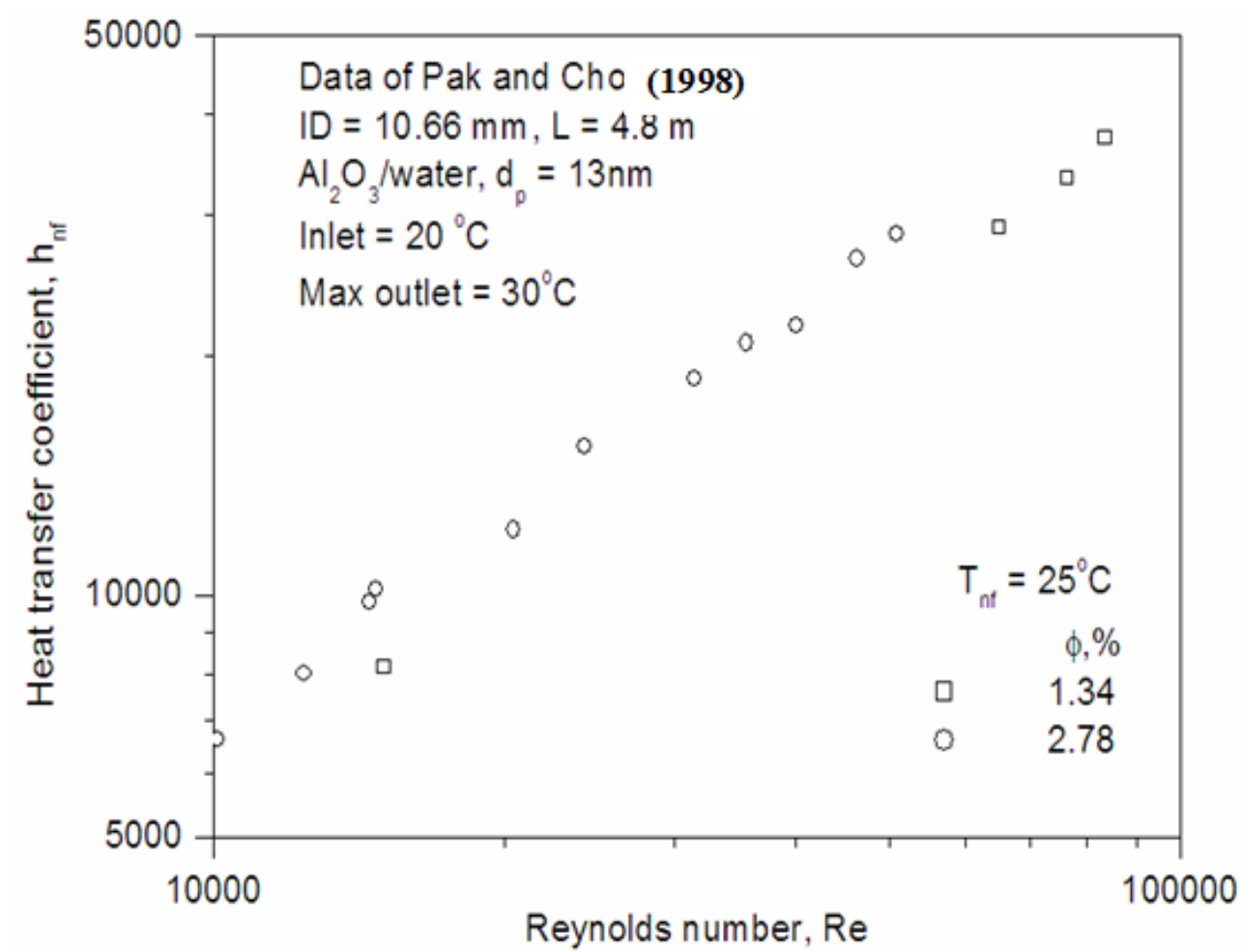

Figure 5. Heat transfer data for $\mathrm{Al}_{2} \mathrm{O}_{3}$ nanofluids.

Similar observations were made by Pak and Cho (1998), who conducted experiments with 13-nm-sized $\mathrm{Al}_{2} \mathrm{O}_{3}$ nanoparticles dispersed in water. They stated that 
the heat transfer coefficient decreased when nanofluid concentration increased to $2.78 \%$, as shown in Figure 5. The authors reported the inlet temperature as $20^{\circ} \mathrm{C}$ with a maximum outlet temperature of $30{ }^{\circ} \mathrm{C}$. The values of enhancement ratio lie above the thick line for temperatures lower than $25^{\circ} \mathrm{C}$, as shown in Figure 6. Similarly, the experimental data of Williams et al. (2008) (not shown) at higher concentrations, is also observed to decrease at higher concentrations. The graph for viscosity-thermal conductivity enhancement indicates a higher value of 4.0 if the operating temperature is less than $32{ }^{\circ} \mathrm{C}$. Further experimental data are required to confirm this observation.

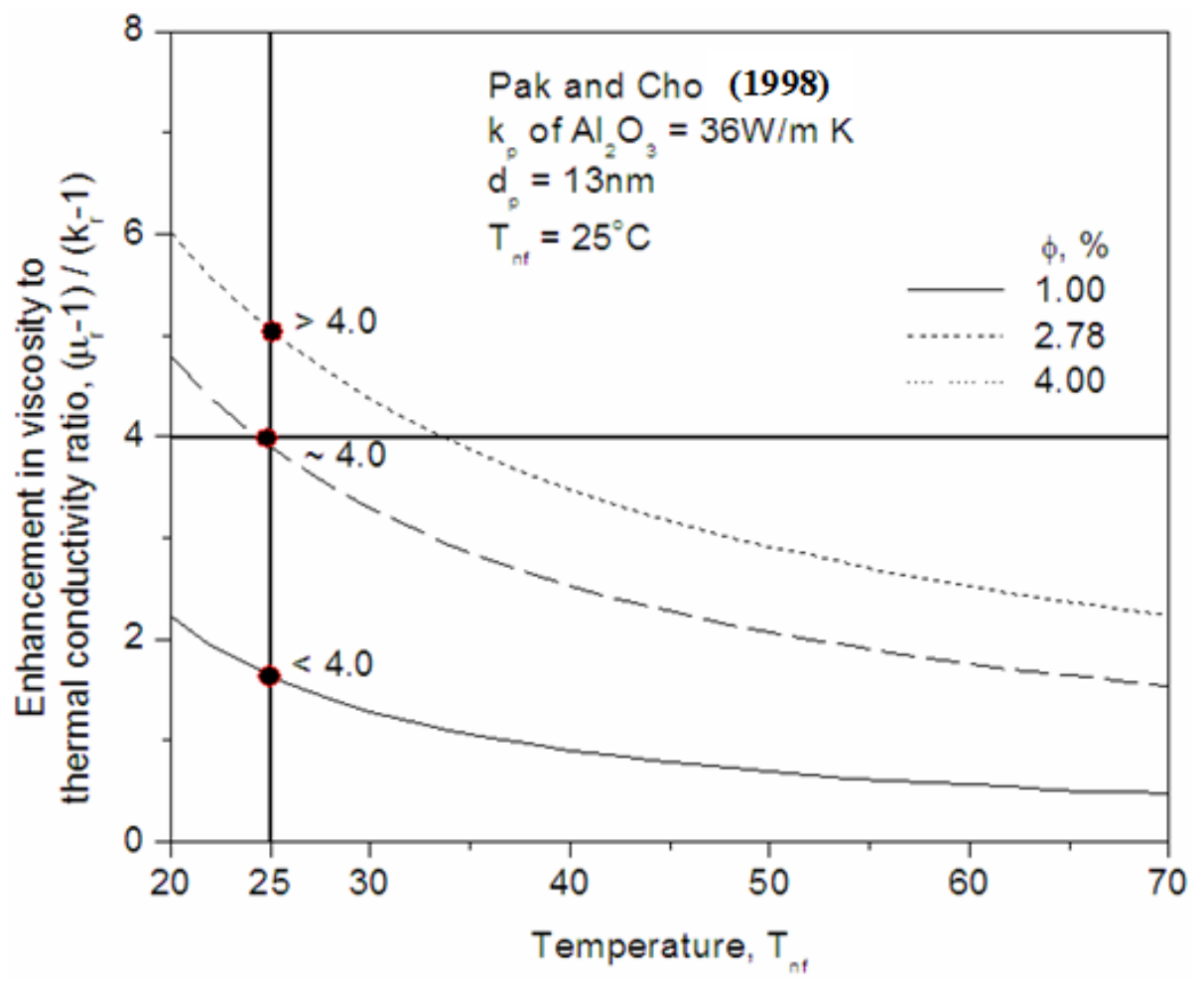

Figure 6. Variation of property enhancement ratio with temperature for $\mathrm{Al}_{2} \mathrm{O}_{3}$.

\section{CONCLUSION}

The thermal conductivity of nanofluids depends on various parameters, such as concentration, temperature, particle size, $\mathrm{pH}$, shape, material, and possibly on the manufacturing process of the nanoparticles. Data on the viscosity of nanofluids, available in the literature, are very limited. Theoretical models for the determination of the thermal conductivity and viscosity of nanofluids have been pursued. Experiments with nanofluids indicate that they higher heat transfer coefficients than the base fluid. No significant increase in pressure drop is reported with nanofluids, compared with values with the base fluid. However, the stability of nanofluids with regard to settlement/agglomeration, especially at higher concentrations, is still a problem for practical applications.

The thermal diffusivity of the material of the nanoparticle is included in the development of the thermal conductivity equation valid for metal and metal oxide nanofluids. Equations are developed for the estimation of thermal conductivity and viscosity of nanofluids considering concentration, temperature, and particle size. The equations have proved successful in predicting a decrease in heat transfer coefficients, 
as observed by Pak and Cho (1998) and Duangthongsuk and Wongwises (2010), under certain operating conditions.

\section{ACKNOWLEDGMENTS}

The research facilities and financial support by Universiti Malaysia Pahang under GRS100354 are gratefully acknowledged.

\section{REFERENCES}

Avsec, J. (2008). The combined analysis of phonon and electron heat transfer mechanism on thermal conductivity for nanofluids. International Journal of Heat and Mass Transfer, 51(19-20), 4589-4598.

Batchelor, G. K. (1977). Effect of Brownian-motion on bulk stress in a suspension of spherical-particles. Journal of Fluid Mechanics, 83(1), 97-117.

Beck, M., Yuan, Y., Warrier, P., \& Teja, A. (2009). The effect of particle size on the thermal conductivity of alumina nanofluids. Journal of Nanoparticle Research, 11(5), 1129-1136.

Brinkman, H. C. (1952). The viscosity of concentrated suspensions and solutions. Journal of Chemical Physics, 20(4), 571-581.

Chon, C. H., \& Kihm, K. D. (2005). Thermal conductivity enhancement of nanofluids by brownian motion. Journal of Heat Transfer, 127(8), 810.

Chon, C. H., Kihm, K. D., Lee, S. P., \& Choi, S. U. S. (2005). Empirical correlation finding the role of temperature and particle size for nanofluid $\left(\mathrm{Al}_{2} \mathrm{O}_{3}\right)$ thermal conductivity enhancement. Applied Physics Letters, 87(15), 1531071-1531073.

Das, S. K., Putra, N., Thiesen, P., \& Roetzel, W. (2003). Temperature dependence of thermal conductivity enhancement for nanofluids. Journal of Heat Transfer, 125(4), 567-574.

Duangthongsuk, W., \& Wongwises, S. (2009). Measurement of temperature-dependent thermal conductivity and viscosity of $\mathrm{TiO}_{2}$ - water nanofluids. Experimental Thermal and Fluid Science, 33(4), 706-714.

Duangthongsuk, W., \& Wongwises, S. (2010). An experimental study on the heat transfer performance and pressure drop of $\mathrm{TiO} 2$-water nanofluids flowing under a turbulent flow regime. International Journal of Heat and Mass Transfer, 53(13), 334-344.

Eastman, J. A., Choi, S. U. S., Li, S., Thompson, L. J., \& Lee, S. (1997). Enhanced thermal conductivity through the development of nanofluids. Proc. Symposium Nanophase and Nanocomposite Materials II, Boston, MA, Materials Research Society.

Hamilton, R. L., \& Crosser, O. K. (1962). Thermal Conductivity of Heterogeneous Two Component Systems. I \& EC Fundamentals, 1, 187-191.

He, Y., Jin, Y., Chen, H., Ding, Y., Cang, D., \& Lu, H. (2007). Heat transfer and flow behaviour of aqueous suspensions of $\mathrm{TiO}_{2}$ nanoparticles (nanofluids) flowing upward through a vertical pipe. International Journal of Heat and Mass Transfer, 50(11-12), 2272-2281.

Heris, S. Z., Etemad, S. G., \& Nasr Esfahany, M. (2006). Experimental investigation of oxide nanofluids laminar flow convective heat transfer. International Communications in Heat and Mass Transfer, 33(4), 529-535. 
Hong, J., Kim, S. H., \& Kim, D. (2007). Effect of laser irradiation on thermal conductivity of ZnO. Journal of Physics, 59, 301-304.

Hwang, K. S., Jang, S. P., \& Choi, S. U. S. (2009). Flow and convective heat transfer characteristics of water-based $\mathrm{Al}_{2} \mathrm{O}_{3}$ nanofluids in fully developed laminar flow regime. International Journal of Heat and Mass Transfer, 52(1-2), 193-199.

Jang, S. P., \& Choi, S. U. S. (2007). Effects of Various parameters on nanofluid thermal conductivity. Journal of Heat Transfer, 129(5), 617-623.

Koo, J., \& Kleinstreuer, C. (2005). Impact analysis of nanoparticle motion mechanisms on the thermal conductivity of nanofluids. International Communications in Heat and Mass Transfer, 32(9), 1111-1118.

Lee, J. H., Hwang, K. S., Jang, S. P., Lee, B. H., Kim, J. H., Choi, S. U. S., \& Choi, C. J. (2008). Effective viscosities and thermal conductivities of aqueous nanofluids containing low volume concentrations of $\mathrm{Al}_{2} \mathrm{O}_{3}$ nanoparticles. International Journal of Heat and Mass Transfer, 51(11-12), 2651-2656.

Lee, S., Choi, S. U. S., Li, S., \& Eastman, J. A. (1999). Measuring thermal conductivity of fluids containing oxide nanoparticles. Journal of Heat Transfer, 121(2), 280289.

Lee, S. W., Park, S. D., Kang, S., Bang, I. C., \& Kim, J. H. (2011). Investigation of viscosity and thermal conductivity of $\mathrm{SiC}$ nanofluids for heat transfer applications. International Journal of Heat and Mass Transfer, 54(1-3), 433438.

Maïga, S. E. B., Nguyen, C. T., Galanis, N., Roy, G., Maré, T., \& Coqueux, M. (2006). Heat transfer enhancement in turbulent tube flow using $\mathrm{Al}_{2} \mathrm{O}_{3}$ nanoparticle suspension. International Journal of Numerical Methods for Heat and Fluid Flow, 16(3): 275-292.

Masuda, H., Ebata, A., Teramae, K., \& Hishinuma, N. (1993). Alteration of thermal conductivity and viscosity of liquid by dispersing ultra fine particles. Netsu Bussei, 4(4), 227-233.

Maxwell, J. C. (1904). A treatise on electricity and magnetism. Cambridge, U.K.: Oxford University Press.

Mintsa, H. A., Roy, G., Nguyen, C. T., \& Doucet, D. (2009). New temperature dependent thermal conductivity data for water-based nanofluids. International Journal of Thermal Sciences, 48(2), 363-371.

Murshed, S. M. S., Leong, K. C., \& Yang, C. (2005). Enhanced thermal conductivity of $\mathrm{TiO}_{2}$ - water based nanofluids. International Journal of Thermal Sciences, 44(4), 367-373.

Nguyen, C. T., Desgranges, F., Galanis, N., Roy, G., Maré, T., Boucher, S., \& Angue Mintsa, H. (2008). Viscosity data for $\mathrm{Al}_{2} \mathrm{O}_{3}$-water nanofluid--hysteresis: is heat transfer enhancement using nanofluids reliable? International Journal of Thermal Sciences, 47(2), 103-111.

Nguyen, C. T., Desgranges, F., Roy, G., Galanis, N., Maré, T., Boucher, S., \& Angue Mintsa, H. (2007). Temperature and particle-size dependent viscosity data for water-based nanofluids- Hysteresis phenomenon. International Journal of Heat and Fluid Flow, 28(6), 1492-1506.

Pak, B. C., \& Cho, Y. I. (1998). Hydrodynamic and heat transfer study of dispersed fluids with submicron metallic oxide particles. Experimental Heat Transfer, 11(2), 151-170. 
Prasher, R., Bhattacharya, P., \& Phelan, P. E. (2006). Brownian motion based convective conductive model for the effective thermal conductivity of nanofluids. Journal of Heat Transfer, 128(6), 588-595.

Prasher, R., Song, D., Wang, J., \& Phelan, P. (2006). Measurements of nanofluid viscosity and its implications for thermal applications. Applied Physics Letters, 89(13), 133108 (133101 to 133103).

Rao, G. S., Sharma, K. V., Chary, S. P., Bakar, R. A., Rahman, M. M., Kadirgama, K., \& Noor, M. M. (2011). Experimental Study on heat transfer coefficient and friction factor of $\mathrm{Al} 2 \mathrm{O} 3$ nanofluid in a packed bed column. Journal of Mechanical Engineering and Sciences, 1: 1-15.

Sundar, L. S., Naik, M. T., Sharma, K. V., Singh, M. K., \& Siva Reddy, T. C. (2011). Experimental investigation of forced convection heat transfer and friction factor in a tube with $\mathrm{Fe} 3 \mathrm{O} 4$ magnetic nanofluid. Experimental Thermal and Fluid Science, 37: 65-71.

Sundar, L. S., \& Sharma, K. V. (2011a). A numerical study heat transfer and friction factor of A12O3 nanofluid. Journal of Mechanical Engineering and Sciences, 1: 99-112.

Sundar, L. S., \& Sharma, K. V. (2011b). Laminar convective heat transfer and friction factor of Al2O3 nanofluid in circular tube fitted with twisted tape inserts. International Journal of Automotive and Mechanical Engineering, 3, 265-278.

Vajjha, R. S., \& Das, D. K. (2009). Experimental determination of thermal conductivity of three nanofluids and development of new correlations. International Journal of Heat and Mass Transfer, 52(21-22), 4675-4682.

Vijaya Lakshmi, B., Subrahmanyam, T., Dharma Rao, V., \& Sharma, K. V. (2012). Turbulent film condensation of pure vapors flowing normal to a horizontal condenser tube - constant heat flux at the tube wall. International Journal of Automotive and Mechanical Engineering, 4, 455-470.

Wang, X., Xu, X., \& Choi, S. U. S. (1999). Thermal conductivity of nanoparticle-fluid mixture. Journal of Thermophysics and Heat Transfer, 13(4): 474-480.

Wen, D., \& Ding, Y. (2004). Experimental investigation into convective heat transfer of nanofluids at the entrance region under laminar flow conditions. International Journal of Heat and Mass Transfer, 47(24), 5181-5188.

Williams, W., Buongiorno, J., \& Hu, L.W. (2008). Experimental Investigation of turbulent convective heat transfer and pressure loss of alumina/water and zirconia/water nanoparticle colloids (Nanofluids) in horizontal tubes. Journal of Heat Transfer, 130(4), 042412-042417.

Yu, W., \& Choi, S. U. S. (2003). The role of interfacial layers in the enhanced thermal conductivity of nanofluids: A renovated maxwell model. Journal of Nanoparticle Research, 5(1), 167-171.

Yu, W., France, D. M., Smith, D. S., Singh, D., Timofeeva, E. V., \& Routbort, J. L. (2009). Heat transfer to a silicon carbide/water nanofluid. International Journal of Heat and Mass Transfer, 52(15-16), 3606-3612. 